operation of cataract extraction, the safety of which must always depend largely on speed and the absence of unnecessary manipulations. One may surely hope that by the practice of a careful technique, the perçentage of suppurations will be reduced. Is it too much to hope that fewer cases will show after operation the condition of "quiet cyclitis" frequently attributed to auto-infection?

\title{
ANNOTATIONS
}

Diploma in Ophthalmic Medicine and Surgery of the Royal College of Physicians of London and the Royal College of Surgeons of England

There are individuals who delight in estimating the possible output of the existing coal mines, and, after calculating the time it will take for them to become exhausted, make our flesh creep with the calamities which are then likely to ensue. They overlook the fact that probably fresh coal fields will be found, and that the ingenuity of man is likely to discover new and more efficient sources of energy than that supplied by coal.

So also, at the commencement of each medical year, we meet with letters and articles in the public press giving the number of new students entering the medical profession, comparing it with the present number of practitioners, and then drawing gloomy pictures of how the profession is becoming overcrowded. These writers overlook the fact that there is a large amount of medical work being carried on by those who have not received any medical training, and that new discoveries are from time to time being made which open up entirely new fields of work for medical practitioners.

By Thomas Young's discovery of astigmatism in 1800, by Airy's introduction of cylindrical lenses for its correction in 1827, and by Donders' great work on accommodation and refraction of the eye in 1864, a new means was opened up for the relief of pain and suffering of an incalculable amount. The provision, however, of medical men competent to undertake the work it involves, even now, falls far short of that which is required. The training and experience which is sufficient to obtain a qualification for the practice of medicine does not ensure adequate skill for the correction of errors of refraction with glasses, nor for the use of the ophthalmoscope.

The Ministry of Health, soon after it was first established, recognized this and applied to the Royal College of Physicians and Surgeons in London to see what could be done to enable them, when required, to select suitable medical practitioners to carry out 
ophthalmic examinations. The Conjoint Examining Board of the two Colleges, with commendable promptitude, took the matter in hand and decided to institute a Diploma in Ophthalmic Medicine and Surgery, the possession of which would be a guarantee that the holder had passed through a suitable course of study in ophthalmology, and that his knowledge of the subject, as tested by an examination, had proved satisfactory.

The Conjoint Board, with the assistance of representatives of the Council of British Ophthalmologists, drew up regulations for the Diploma, which were approved of by the Councils of the two Colleges, and the first examination for it was held in July, 1920.

It was not the first Diploma in Ophthalmology to be established in this country, one having been instituted at Oxford in 1910, through the foresight and energy of the late Mr. R. W. Doyne. The conditions required of candidates before presenting themselves for examination are very similar for the two Diplomas. For both candidates have to possess registerable medical qualifications, or be graduates in medicine and surgery of certain recognised Universities. For both evidence has to be produced of a year's attendance at an Ophthalmic Clinic in connection with a recognized institution. For the Oxford Diploma a term's attendance at a course of instruction at Oxford is essential. For the Colleges' Diploma it is not stated where the required courses of instruction have to be pursued. For the Oxford Diploma one examination, comprising all subjects, is held once a year. The examination for the Colleges' Diploma is divided into two parts; the first dealing with anatomy and embryology, physiology and elementary optics ; and the second with ophthalmic medicine and surgery and ophthalmic pathology. Both parts of the examination are held twice a year, in January and July. A candidate who has passed the first part can, if he desires, present himself for the second part the same month.

That this Diploma of Ophthalmology established by the Royal Colleges in London is meeting with increasing recognition and favour, is shown by the number of candidates that present themselves for it. For Part I. there were, in July, 1920, 25 candidates; in January, 1921, 34 ; and in July, 1921, 31. For Part II. there were in July, 1920, 11 candidates; in January, 1921, 9; and in July, 1921,25 . The standard of marking for the examination is in accordance with the object for which the Diploma was established; it is such as a medical man who has attended a year's practice at an ophthalmic clinic might be expected to attain. The standard is not equal to that which might be required for appointment as ophthalmic surgeon to a hospital, or for a post as teacher of ophthalmology. This is brought out by the number of candidates referred at each of the examinations. Of the 90 candidates who presented themselves for the first part 27 were referred; of the 45 
candidates who presented themselves for the second part 6 were referred.

An indirect benefit to ophthalmology, arising out of the establishment of the Diploma, has been the stimulus it has given to the study of the preliminary scientific subjects upon which the practice of ophthalmology ought always to be based.

The few classes held in former days dealing specially with ophthalmic anatomy, physiology, and optics, were but scantily attended. Now that an examination in these subjects has to be passed to obtain the Diploma, a demand for instruction in them has arisen. We find that at three of the special ophthalmic hospitals in London the necessary provision to meet this demand is being made.

At the Royal London Ophthalmic Hospital, Moorfields, special courses in the preliminary subjects are held twice a year, immediately preceding the date of the examination. The lectures on physiology are given by one of the surgeons of the hospital, $\mathrm{Mr}$. - Herbert Parsons, F.R.S., lectures on anatomy are given by Mr. Hillman, demonstrator of anatomy at the Middlesex Hospital. Lectures on optics are given by Mr. Hopwood, lecturer on physics at St. Bartholomew's Hospital.

In conjunction with the Royal Westminster Ophthalmic Hospital a complete course in the subjects for Part I of the examination for the Diploma, is held at King's College, lasting over a period of four weeks. The Central London Ophthalmic Hospital also advertises courses of instruction in these subjects arranged in conformity with the requirements of the Conjoint Board for the Diploma.

At the National Hospital for Paralyzed and Epileptic a special course of lectures and demonstrations in the neurological aspects of ophthalmology has also been instituted in view of this examination, and has been well attended.

Ophthalmic surgeons of the present day, when they recall the somewhat haphazard fashion in which they had to acquire instruction in these fundamental scientific bases of their art, may well envy the coming generation the new facilities which are now provided for them.

\section{The Standardization of the Axes of Cylindrical Lenses}

The report on the standardization of the notation of the axes of cylinders was published in this Journal (July, 1921).

The Council of British Ophthalmologists considered in detail eight different notations in use, and gave good reasons for the adoption of one of them, namely, in their own words, "That in 